\title{
Rocky shores of a major southern African Marine Protected Area are almost free from intertidal invertebrate alien species
}

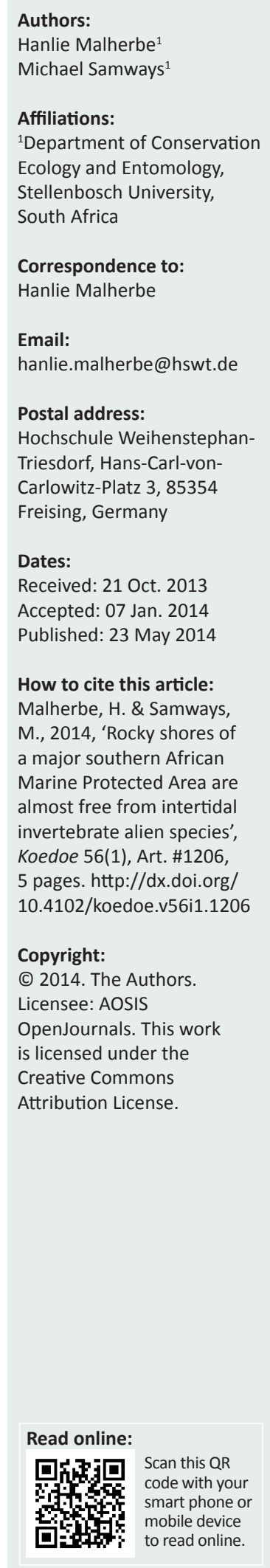

A major threat to marine ecosystems is the establishment and proliferation of invasive alien species. This study addresses gaps in our knowledge regarding marine alien invertebrate species in the Kogelberg Biosphere Reserve (KBR) and adjacent Betty's Bay Marine Protected Area (MPA) in the Western Cape of South Africa, together a potentially important area for south-coast marine conservation. Understanding the distribution and geographical expansion of these species is critical for conservation planning. A quantitative systematic survey of the intertidal rocky shore region was undertaken. The mytilid Mediterranean mussel, Mytilus galloprovincialis, and the bryozoan Watersipora subtorquata were the only alien species recorded along the coastline, which included the MPA. The abundance of M. galloprovincialis was significantly higher outside the MPA, and the abundance of W. subtorquata was significantly higher inside the MPA. With only two alien species recorded, the Betty's Bay MPA and its surroundings support relatively few marine alien species with regards to rocky shore invertebrate biodiversity.

Conservation implications: It is important that the Betty's Bay MPA and its adjacent coastline maintain its current status as an area with relatively few marine alien species. The conservation implications on management require routine surveys of this region to detect early introductions of any additional species.

\section{Introduction}

The appearance of invasive alien species is a threat to marine reserves and marine protected areas (MPAs). Under favourable conditions, coastal invaders spread quickly over extensive geographical ranges, occasionally reaching marine reserves and MPAs (Grosholz 2002). Once a species becomes established and spreads, it may have adverse effects on the indigenous marine biodiversity and marine communities (Bax et al. 2003; Molnar et al. 2008; Padilla \& Williams 2004). For example, the collapse of the bivalve fisheries industry of eastern North America resulted from the introduction of the European shore crab Carcinus maenas. A halt in the production of San Francisco Bay's, USA phytoplankton arose from the invasion of the Asian clam Potamocorbula amurensis (Grosholz 2002). Furthermore, the introduction of the comb jellyfish Mnemiopsis leidyi in the Black Sea resulted in a rapid decrease of phytoplankton blooms and consequently the collapse of various fish stocks (Shiganova 1998). In South Africa, the invasion of the mytilid Mediterranean mussel, Mytilus galloprovincialis, has substantially altered certain local mussel beds, increasing mussel biomass along the coastline (Robinson et al. 2005) and displacing the indigenous mussels Aulacomya ater and Choromytilus meridionalis (Hockey \& Van Erkom Schurink 1992). Mytilus galloprovincialis is considered the most invasive marine invertebrate species in South Africa. However, on a positive note, the endemic African black oystercatcher, Haematopus moquini, has adapted its diet to mainly feed on M. galloprovincialis. This has enabled a significant recovery of the population of H. moquini (Hockey \& Van Erkom Schurink 1992). Also, local human communities along the west coast of South Africa have reaped benefits from the introduction of M. galloprovincialis, with a small-scale mussel culturing industry now in operation along this coast. Rocky shore invertebrate alien species have appeared along the South African coastline. Some of these have established and spread in their new home range, invading marine reserves and MPAs, and their surroundings (Griffiths, Mead \& Robinson 2009a; Laird \& Griffiths 2008; Robinson, Griffiths \& Kruger 2004; Robinson et al. 2005). The Betty's Bay MPA and its surroundings are susceptible to such invasive species. It is therefore critical to have an understanding of the current status of this region. The aim of this study is to specifically fill gaps in our knowledge of the status of intertidal rocky shore invertebrate alien species of the Betty's Bay MPA and surroundings, and to determine the extent of invasion of these species in the region. 


\section{Research method and design Study area}

This study was conducted in the Kogelberg Biosphere Reserve (KBR) and the adjacent MPA, $90 \mathrm{~km}$ south-east of Cape Town in the Western Cape province, South Africa. The KBR coastline is diverse, characterised by sandy beaches, rocky shores, estuary runoffs, subtidal kelp forests and reefs. The Betty's Bay MPA was first declared in 1981 as the H.F. Verwoerd Marine Reserve (Tunley 2009). Under the Marine Living Resources Act (Act No. 18 of 1998), the marine reserve was proclaimed the Betty's Bay MPA in 2000. Seven principal rocky shore research sites were selected, and are

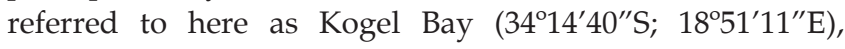

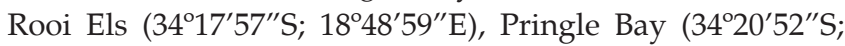
$\left.18^{\circ} 49^{\prime 2} 29^{\prime \prime} \mathrm{E}\right)$, Stony Point (34 22'14"S; 18 53'41"E), Betty's Bay main beach ( $34^{\circ} 22^{\prime} 01^{\prime \prime} \mathrm{S}$; $\left.18^{\circ} 53^{\prime} 58^{\prime \prime} \mathrm{E}\right)$, Jock's Bay (34 $21^{\circ} 26^{\prime \prime} \mathrm{S}$;

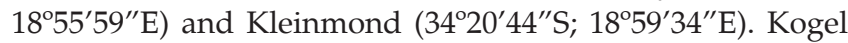
Bay, Rooi Els and Pringle Bay are located to the west of the MPA; Stony Point, Betty's Bay main beach and Jock's Bay are located within the MPA; and Kleinmond is located to the east of the MPA (Figure 1). Distances between the study sites varied considerably due to interspersed sandy beaches and estuary runoffs. The longest distance, between Kogel Bay and
Rooi Els, was 7 km, and the shortest distance, between Stony Point and Betty's Bay main beach, was 800 m. It was evident that a wave exposure gradient exists along the KBR coastline. Stony Point, Betty's Bay main beach and Pringle Bay were recognised as sheltered sites, Jock's Bay and Kleinmond were recognised as semi-exposed sites, and Kogel Bay and Rooi Els were recognised as exposed sites. It was also observed that the coastline of the MPA is sheltered compared to the coastline to the west and east of the MPA.

\section{Data collection and analyses}

Transects were established from low to high shore at each of the seven selected study sites. The number of transects per site varied depending on the size of the site. The greatest number of transects at a specific site was nine, and the least was three. A total number of 42 transects were used, of which 20 were inside the MPA, and 22 outside. Six intertidal $1 \mathrm{~m}^{2}$ sampling units (SUs) were stratified per entire transect from low to high shore of the intertidal zone. Zonation of rocky shores is subjective. However, the high-, mid- and low shore along the KBR supports a unique composition of rocky shore marine invertebrate species living in rock pools or on bare rock surfaces. Sampling units were designated to rock

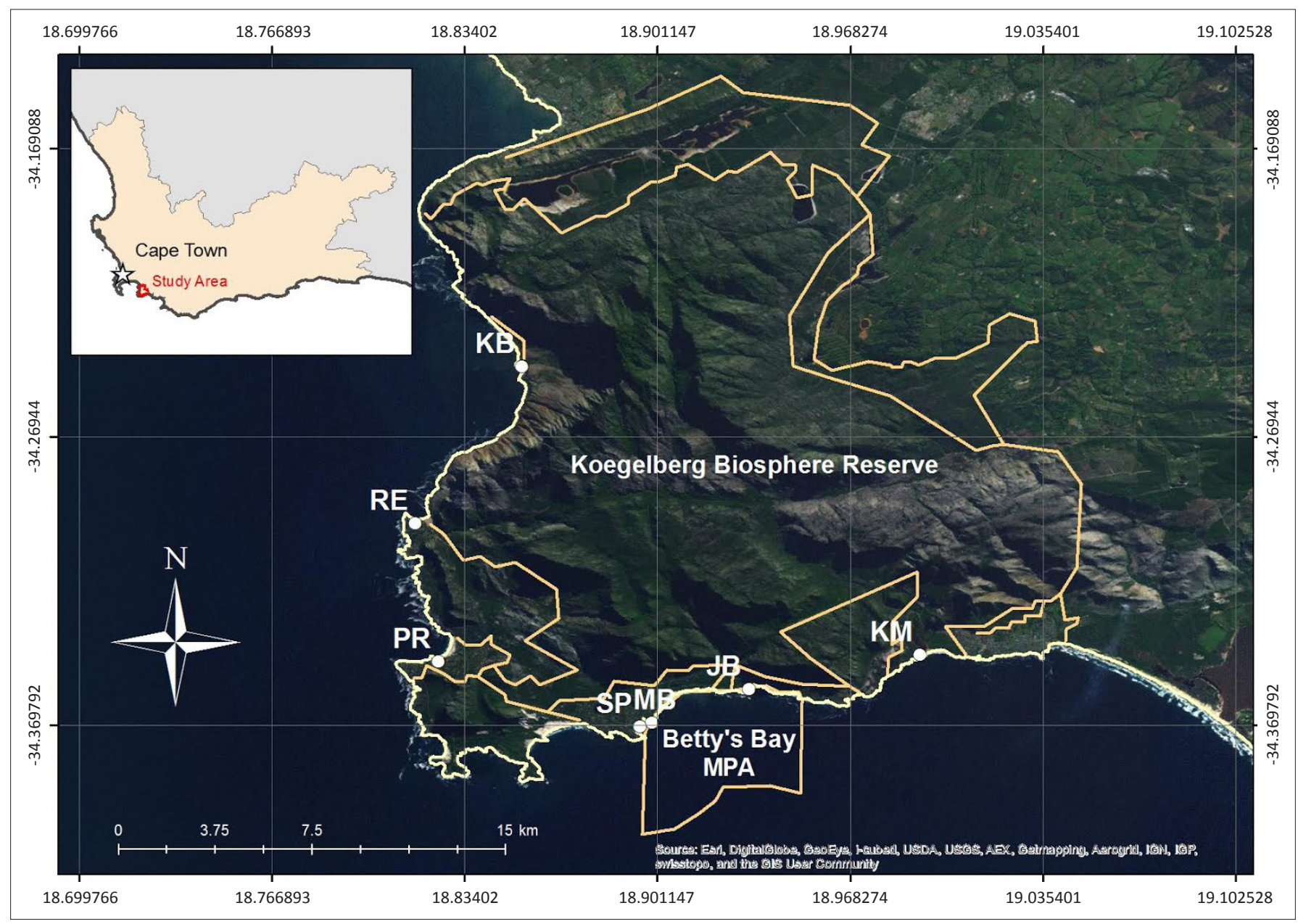

Source: ArcGIS version 10.1, 2012, computer software, Esri, Redlands

KB, Kogel Bay; RE, Rooi Els; PR, Pringle Bay; SP, Stony Point; MB, Betty's Bay main beach; JB, Jock's Bay; KM, Kleinmond.

FIGURE 1: Location of study sites along the Kogelberg Biosphere Reserve coastline, Western Cape province, South Africa. 
pools and bare rock surfaces. The number of SUs per shore region differed to include all rocky shore marine invertebrate species in the scope of the study. Two rock pool SUs and one rock surface SU were allocated to the low shore. One rock pool SU and one rock surface SU were allocated to the mid shore. One rock pool was allocated to the high shore. The SUs of the low shore were referred to as low tide pool seaward, low tide pool leeward and low tide rock surface. The SUs of the mid shore were referred to as mid tide pool and mid tide rock surface. The SU of the high shore was referred to as high tide pool.

Quantitative systematic sampling was done from October 2010 to December 2010. In order not to overlook any alien species, an in situ visual count of all focal rocky shore marine invertebrate species, except the phylum Annelida, order Isopoda, and the order Amphipoda, was done at each SU. In the case of colony-forming species, a count value was allocated to the area covered by the species. For each $1 \mathrm{~cm}^{2}$ a value of one was allocated. The counting method for each species was consistent. The time spent at each SU depended on the time needed to count each species. Some rock pool species prefer to reside under loose rocks. Loose rocks were always present in the low tide pool seaward, low tide pool leeward and the mid tide pool. No more than three mediumsized rocks in each of the latter rock pools were overturned. In the case of smaller rocks, two rocks were overturned and counted as one medium-sized rock.

Generalized linear models (GLMs) were used to firstly test for significant differences in mean abundance of the identified marine alien species across the MPA and non-MPA (NMPA), and, secondly, to test for a significant difference across the study sites (O'Hara 2009; Zuur, Ieno \& Elphick 2010). To test for a significant difference in mean abundance across the MPA and NMPA, all the SUs in the MPA were pooled together, and all the SUs in the NMPA were pooled together. To test for a significant difference in mean abundance across the study sites, all the SUs per study site were pooled together. These GLMs were calculated with normal distribution (with identity link functions) for all data, as means were $>5$, and the minimum number of successes and failures were $<5$ (Bolker et al. 2009). As these analyses showed no overdispersion of variances compared to the models, Wald $\chi^{2}(Z)$, statistics were calculated using the penalised quasilikelihood technique (Bolker et al. 2009). Statistical analysis software (SAS) package (Statistical Analysis Software 2006) version 9.1.3 was used to run the analyses.

\section{Results and discussion}

Only two marine alien invertebrate species, the alien Mediterranean mussel, M. galloprovincialis, and the alien bryozoan Watersipora subtorquata, were recorded along the rocky shores of the KBR. It is evident that M. galloprovincialis was not evenly distributed along the rocky shores of the KBR. Mean abundance of M. galloprovincialis was significantly greater outside the MPA $\left(18.3 \mathrm{~m}^{-2}\right)$ than inside (no individuals recorded) $(d f=1, Z=4.38, p \leq 0.05$, Figure 2).
There was a significant difference in mean abundance of M. galloprovincialis across the study sites, with a significantly greater abundance at Kogel Bay than at any other sites ( $d f=6, Z=25.13, p \leq 0.001$, Figure 3). It has been documented that the level of wave exposure affects the distribution and abundance of M. galloprovincialis, which is characteristic at semi-exposed and exposed sites (Blamey \& Branch 2009). This appears to be the case along the KBR coastline since the rocky shores, with the exception of Pringle Bay, is subjected to a greater wave exposure outside the MPA, particularly at Kogel Bay and Rooi Els. In all likelihood, the abundance of M. galloprovincialis could be higher along the coastal region to the west and east of the MPA and at the study site Jock's Bay located at the western boarder of the MPA than was measured, since by chance the selected study sites and sampling units were placed at areas in which M. galloprovincialis was absent. In contrast to $M$. galloprovincialis, $W$. subtorquata was significantly more abundant inside the MPA $(d f=1, Z=5.97, p \leq 0.05)$ with a mean abundance of $17.3 \mathrm{~m}^{-2}$ compared to $5.5 \mathrm{~m}^{-2}$

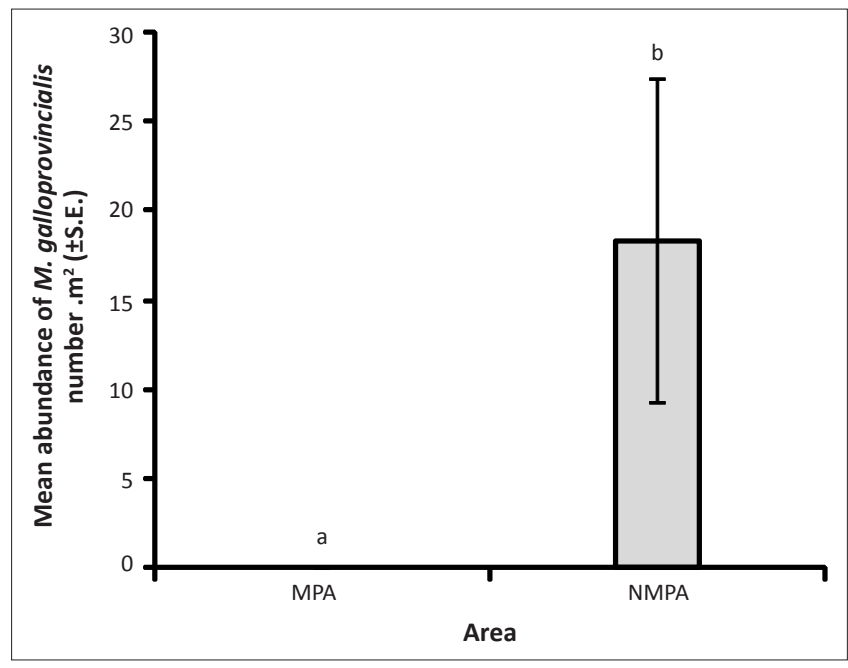

M. galloprovincialis, Mytilus galloprovincialis; S.E., standard error; MPA, marine protected area; NMPA, non-marine protected area.

FIGURE 2: Abundance of Mytilus galloprovincialis in the marine protected area and non-marine protected area.

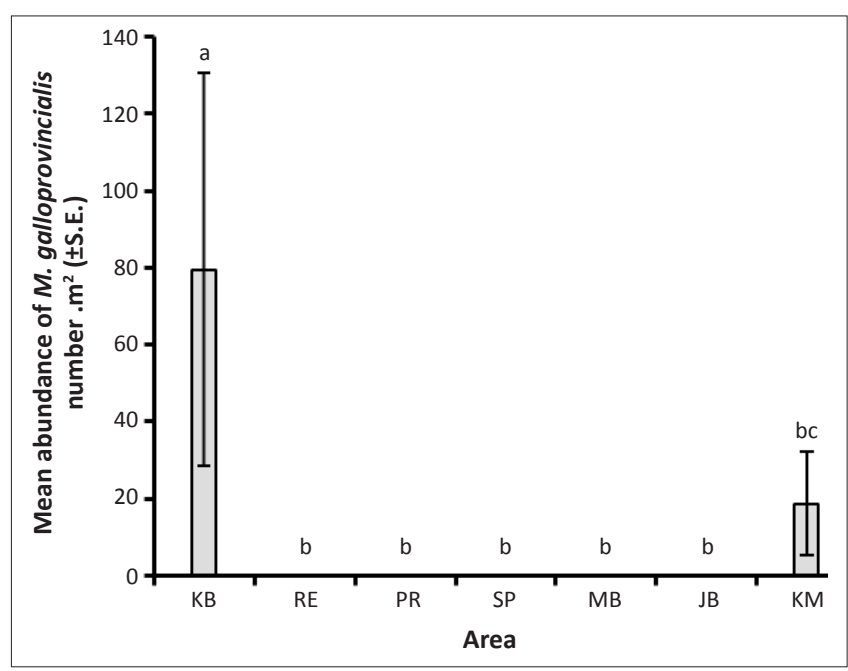

M. galloprovincialis, Mytilus galloprovincialis; S.E., standard error; KB, Kogel Bay; RE, Rooi Els; PR, Pringle Bay; SP, Stony Point; MB, Betty's Bay main beach; JB, Jock's Bay; KM, Kleinmond. FIGURE 3: Abundance of Mytilus galloprovincialis at the different study sites. 


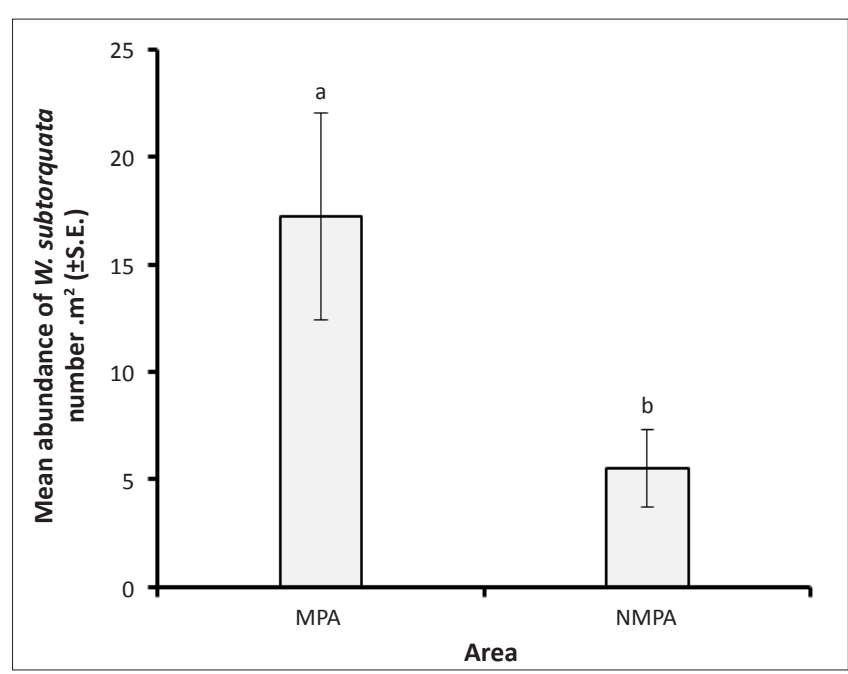

W. subtorquata, Watersipora subtorquata; S.E., standard error; MPA, marine protected area; NMPA, non-marine protected area.

FIGURE 4: Abundance of Watersipora subtorquata in the marine protected area and non-marine protected area.

outside the MPA (Figure 4). There was no significant difference in mean abundance of $W$. subtorquata across the study sites $(d f=6, Z=8.70, p>0.05)$. From the former finding, it could be concluded that this species prefers the sheltered conditions of the MPA. However, there is no information on the effects of wave exposure on W. subtorquata in South Africa. The difference in the abundance of W. subtorquata along the Kogelberg Biosphere Reserve coastline was in all likelihood from the integrated functioning of various factors.

Various introductions of marine alien invertebrate species and invasions along the coast of South Africa have been documented. Mytilus galloprovincialis, the European shore crab C. maenas, and the periwinkle Littorina saxatilis have naturalised outside the boundaries of the Saldanha Bay harbour situated in the West Coast National Park (WCNP) Marine Reserve, South Africa. The reserve forms part of the Saldanha Bay-Langebaan Lagoon system. A survey conducted by Robinson et al. (2004) indicated that the abundance of M. galloprovincialis within the WCNP was low; L. saxatilis was confined to the lagoon and salt marshes, the alien anemone Sagartia ornata was confined to the lagoon, and no live individuals of $C$. maenas were recorded. Other identified marine alien invertebrate species such as the ascidians Diplosoma listerianum, Ciona intestinalis and Ascidiella aspersa are confined to the harbour. It is also recognised that the Saldanha Bay-Langebaan Lagoon system supports the most marine alien species along the South African coast (Robinson et al. 2004). A survey conducted by Robinson et al. (2005) indicates that M. galloprovincialis is present along the west coast, south coast and east coast, almost reaching East London. Significant populations of the Pacific barnacle Balanus glandula have been detected along the west coast (Griffiths et al. 2009a, 2009b) from Misty Cliffs to Elands Bay (Laird \& Griffiths 2008). The west coast supports a prime example of upwelling. Pineda and López (2002) found that the settlement of $B$. glandula larvae increased with highfrequency internal motion. This may explain the presence of this species along the cool waters of west coast and its absence along the KBR coastline. Watersipora subtorquata has been recorded along the coast of the Western and Eastern Cape provinces (Branch et al. 2010). The former and latter geographical regions are interspersed with marine reserves and MPAs, which suggests that these coastal areas of conservation may be invaded by marine alien invertebrate species. Since many marine and estuarine alien species in South Africa have been overlooked (Mead et al. 2011), the current status of marine alien invertebrate species along the shores of South Africa, including marine reserves and MPAs, may be different. This is a challenge that must be addressed.

With only two alien species recorded along the rocky shores of the KBR, it is evident that the Betty's Bay MPA supports relatively few marine alien species relating to rocky shore invertebrate biodiversity, particularly compared to the wellstudied WCNP. The inclusion of the Saldanha Bay harbour in the WCNP makes this conservation region much more susceptible to the invasion of marine alien invertebrate species. In the case of the Betty's Bay MPA, it has more sheltered shores, which do not support the proliferation of M. galloprovincialis. It is suggested that the sheltered nature of the Betty's Bay MPA should be considered the primary reason for its good condition regarding $M$. galloprovincialis invasion. It is therefore not considered feasible to implement marine reserves and MPAs to decrease the geographical extent of marine alien species. Marine alien species will potentially invade any favourable region along the coast. Identifying and eliminating pathways is considered to be the only practical method in preventing possible introductions and proliferation of marine alien species. Prevention is therefore critical for effective conservation (Bax et al. 2003).

It is of concern that many MPAs in South Africa, including the Betty's Bay MPA, function as isolated units. It is not viable to focus only on isolated regions of this highly integrated and vast open system. Managing large, multipurpose MPAs is of great interest as it provides opportunities to conserve highly mobile species, and protects demarcated regions from pollution and unwanted negative impacts from human activities (Hoegland, Sumaila \& Farrow 2001). It is also suggested that habitat heterogeneity must be considered when selecting priority areas for coastal conservation. A greater diversity of rocky shore species are conserved when applying the habitat heterogeneity approach rather than the hotspot approach. Furthermore, the level of wave exposure plays an important role in defining the habitat types of rocky shores (Blamey \& Branch 2009). The sheltered nature of the Betty's Bay MPA may lack specific habitat types, therefore decreasing the species richness being protected . This emphasizes the importance of taking a more holistic management approach (Mora et al. 2006). In 2010, only 9\% of all South Africa's MPAs were declared as no-take MPAs (Griffiths et al. 2010), although shore angling is a resource utilization activity that is allowed in the Betty's Bay MPA (Tunley 2009). It is evident that the Betty's Bay MPA will function more adequately if managed as a large, multi- 
purpose MPA. This protected coastal region unfortunately experiences much pressure from overexploitation, development (Tunley 2009) and abalone poaching (Stanvliet et al. 2004). A current study is underway to investigate the status of fish communities inside and outside the MPA. It should, however, be noted that an African penguin Spheniscus demersus colony (a Red List species), as well as other species, particularly the abalone Haliotis midae and the West Coast rock lobster, Jasus lalandii, are protected within the MPA (Tunley 2009).

\section{Conclusion}

With only two alien species, the mytilid mussel, M. galloprovincialis, and the bryozoan W. subtorquata, being recorded, this study revealed that the southern African coastline around the Betty's Bay MPA has been invaded by relatively few marine alien species with regards to rocky shore invertebrate biodiversity. Fortunately, the abundance of these two species in the Betty's Bay MPA is relatively low. The MPA is therefore in good condition regarding intertidal invasive alien species. Marine introductions and invasions are considered irreversible (Bax et al. 2003) and eradication of these two species along this coastline is not viable. Nevertheless, we recommend routine surveys of this region are conducted to detect early introductions of any additional species.

\section{Acknowledgments}

We thank CapeNature and the Department of Environmental Affairs, Marine Coastal Management, for the provision of research permits (Danelle Kleinhans, dkleinhans@ capenature.co.za, ref. 1/2/1/6/5/F8, permit no. AAA004-00481-0035). We also thank C.L. Griffiths (Department of Zoology, University of Cape Town - Marine Research Institute) for assistance in the identification of specimens, and J.S. Pryke (Department of Conservation Ecology and Entomology, Stellenbosch University) for assistance with statistical analyses. M.J. Samways acknowledges funding from the National Research Foundation.

\section{Competing interests}

The authors declare that they have no financial or personal relationships that may have inappropriately influenced them in writing this article.

\section{Authors' contributions}

H.M. (University of Stellenbosch) designed the methods, carried out the field surveys, interpreted the results, and wrote the first draft of the manuscript. M.J.S. (University of Stellenbosch) assisted with the design of the methods and coprepared the manuscript.

\section{References}

ArcGIS version 10.1, 2012, computer software, Esri, Redlands.

Bax, N., Williamson, A., Aguero, M., Gonzales, E. \& Geeves, W., 2003, 'Marine invasive alien species: A threat to global biodiversity', Marine Policy 27, 313-323. http:// dx.doi.org/10.1016/S0308-597X(03)00041-1

Blamey, L.K. \& Branch, G.M., 2009, 'Habitat diversity relative to wave action on rocky shores: Implications for the selection of marine protected areas', Aquatic Conservation Marine and Freshwater Ecosystems 19, 645-657. http://dx.doi. org/10.1002/aqc.1014

Bolker, B.M., Brooks, M.E., Clark, C.J., Geange, S.W., Poulsen, J.R., Stevens, M.H. et al., 2009, 'Generalized linear mixed models: A practical guide for ecology and evolution', Trends in Ecology \& Evolution 24, 127-135. http://dx.doi. org/10.1016/j.tree.2008.10.008

Branch, G.M., Griffiths, C.L., Branch, M.L. \& Beckley, L.E., 2010, Two Oceans - A guide to the marine life of southern Africa, Struik Nature, Cape Town.

Griffiths, C.L., Mead, A. \& Robinson, T.B., 2009a, 'A brief history of marine bio invasions in South Africa', African Zoology 44, 241-247. http://dx.doi. org $/ 10.3377 / 004.044 .0212$

Griffiths, C.L., Robinson, T.B. \& Mead, A., 2009b, 'The Status and Distribution of Marine Alien Species in South Africa', Ecological Studies 204, 393-408.

Griffiths, C.L., Robinson, T.B., Lange, L. \& Mead, A., 2010, 'Marine biodiversity in South Africa: An evaluation of current states of knowledge', Plos One 5, 1-13. http:// dx.doi.org/10.1371/journal.pone.0012008

Grosholz, E., 2002, 'Ecological and evolutionary consequences of coastal invasions', Trends in Ecology \& Evolution 17, 22-27. http://dx.doi.org/10.1016/S01695347(01)02358-8

Hockey, P.A.R. \& Van Erkom Schurink, C., 1992, 'The invasion biology of the mussel Mytilus galloprovincialis on the southern-African coast', Transactions of the Royal Society of South Africa 48, 123-139. http://dx.doi. Transactions of the Royal Society
org $1080 / 00359199209520258$

Hoegland, P., Sumaila, U.R. \& Farrow, S., 2001, Marine Protected Areas, Academic Press, Massachusetts.

Laird, M.C. \& Griffiths, C.L., 2008, 'Present distribution and abundance of the introduced barnacle Balanus glandula Darwin in South Africa', African Journal of Marine Science 30, 93-100. http://dx.doi.org/10.2989/AJMS.2008.30.1.9.459

Mead, A., Carlton, J.T., Griffiths, C.L. \& Rius, M., 2011, 'Introduced and cryptogenic marine and estuarine species of South Africa', Journal of Natural History 45, 2463-2524. http://dx.doi.org/10.1080/00222933.2011.595836

Molnar, J.L., Gamboa, R.L., Revenga, C. \& Spalding, M.D., 2008, 'Assessing the global threat of invasive species to marine biodiversity', Frontiers in Ecology and the Environment 6, 485-492. http://dx.doi.org/10.1890/070064

Mora, C., Andrefouet, S., Costello, M.J., Kranenburg, C., Rollo, A., Veron, J. et al. 2006 , 'Coral reefs and the global network of marine protected areas', Science 312 1750-1751. http://dx.doi.org/10.1126/science.1125295

O'Hara, R.B., 2009, 'How to make models add up - a primer on GLMMs', Annales Zoologici Fennici 46, 124-137. http://dx.doi.org/10.5735/086.046.0205

Padilla, D.K. \& Williams, S.L., 2004, 'Beyond ballast water: Aquarium and ornamental trades as sources of invasive species in aquatic ecosystems', Frontiers in Ecology and the Environment 6, 485-492.

Pineda, J. \& López, M., 2002, 'Temperature, stratification and barnacle larval settlement in two Californian sites', Continental Shelf Research 22, 1183-1198. http://dx.doi.org/10.1016/S0278-4343(01)00098-X

Robinson, T.B., Griffiths, C.L. \& Kruger, N., 2004, 'Distribution and status of marine invasive species in and bordering the West Coast National Park', Koedoe 47, 7987. http://dx.doi.org/10.4102/koedoe.v47i1.73

Robinson, T.B., Griffiths, C.L., McQuiad, C. \& Rius, M., 2005, 'Marine alien species of South Africa - status and impacts', African Journal of Marine Science 27, 297-306. http://dx.doi.org/10.2989/18142320509504088

Statistical Analysis Software version 9.1., 2006, computer software, SAS Institute Inc. Cary, North California.

Shiganova, T.A., 1998, 'Invasion of the Black Sea by the ctenophore Mnemiopsis leidyi and the recent changes in pelagic community structure', Fisheries Oceanography 7, 305-310. http://dx.doi.org/10.1046/j.1365-2419.1998.00080.x

Stanvliet, R., Jackson, J., Davis, G., De Swardt, C., Mokhoele, J., Thom, Q. et al., 2004 'The UNESCO biosphere reserve concept as a tool for urban sustainability - The CUBES Cape Town Case-Study', Urban Biosphere and Society: Partnership of Cities 1023, 80-104.

Tunley, K., 2009, 'State of Management of South Africa's Marine Protected Areas', in WWFSouth Africa Report Series, viewed December 2013, from http://assets.wwfza. panda.org/downloads/mpastateofmanagementreport04nov2009weblowerdpi. pdf

Zuur, A.F., leno, E.N. \& Elphick, C.S., 2010, 'A protocol for data exploration to avoid common statistical problems', Methods in Ecology and Evolution 1, 3-14. http:// dx.doi.org/10.1111/j.2041-210X.2009.00001.x 